\title{
Use of PCR to identify enteroaggregative Escherichia coli as an important cause of acute diarrhoea among children living in Calcutta, India
}

\author{
SHANTA DUTTA, SANGITA PAL, S. CHAKRABARTI, P. DUTTA and B. MANNA \\ National Institute of Cholera and Enteric Diseases P-33, CIT Road, Scheme XM, Beliaghata, Calcutta 700010 , \\ India
}

\begin{abstract}
The importance of enteroaggregative Escherichia coli (EAggEC) as a possible aetiological agent of acute diarrhoea among children in Calcutta, India, was investigated. Simultaneously the use of a previously described PCR diagnostic system was assessed for its ability to identify EAggEC infection. $E$. coli strains isolated during a 1-year casecontrol study from faecal samples of 388 children aged $<5$ years, with or without diarrhoea, were examined for EAggEC by HeLa cell adherence assay in parallel with a PCR assay with primers generated from an EAggEC DNA probe. A blind comparison was made between the two methods to determine their diagnostic potential. $E$. coli isolates that adhered to HeLa cells in an aggregative pattern were the sole isolates significantly more often in 254 cases $(9 \%)$ than in 134 control $(2 \%)$ children. Age stratification showed that EAggEC were isolated more frequently from children aged $<36$ months. The EAggEC isolates belonged to several $O$ serogroups and showed multiple drug resistance. Both methods were positive for 26 samples, nine samples were positive by PCR alone and seven samples were positive by culture alone, thus indicating a $78 \%$ sensitivity and $97 \%$ specificity for the PCR assay. EAggEC is an important aetiological agent of acute diarrhoea among infants in and around Calcutta, and the PCR diagnostic system may be useful to identify such infection in epidemiological studies.
\end{abstract}

\section{Introduction}

Bacterial adherence to the intestinal mucosa is characteristic of Escherichia coli strains that cause diarrhoea in infants [1]. HEp-2 or HeLa cell in-vitro adherence assays are used to identify enteroadherent $E$. coli [2]. Three distinct patterns of adherence are described [3] - localised adherence, diffuse adherence and aggregative adherence. Enteroaggregative E. coli (EAggEC), which are characterised by typical mannose-resistant stacked-brick-like adherence to cultured $\mathrm{HeLa}$ (or HEp-2) cell surfaces as well as on plastic or glass surfaces [2, 3], are of particular interest because of their unusual microbiological properties [4] and their epidemiological association with persistent diarrhoea in children in developing countries [5-7].

At present, the epidemiology of infection caused by EAggEC remains controversial. Although its associa-

Received 10 Oct. 1998; revised version accepted 10 March 1999.

Corresponding author: Dr S. Dutta (e-mail: icmrnicd@ren. nic.in). tion with acute diarrhoea has been documented by some workers $[8,9]$, others have reported inconclusive results $[10,11]$. EAggEC strains have also been isolated in outbreaks affecting young children and elderly patients [12-14].

The pathogenesis of EAggEC diarrhoea is also poorly understood. The presence of a large plasmid (60 MDa) confers the expression of the aggregative phenotype [4], which for certain strains is mediated by aggregative adherence fimbriae (AAFS) [15, 16]. EAggEC strains also secrete putative heat-stable and heat-labile enterotoxins $[17,18]$, but their role in diarrhoea has not yet been established [19]. More recently an autotransporter enterotoxin has been detected in isolates from a severe outbreak of diarrhoea [20].

Though EAggEC was originally identified by a HEp-2 cell adherence assay, the phenotypic characteristics are sometimes difficult to discern and subject to individual interpretation, as observed in a previous report [21]. Therefore, the development of genetic diagnostic tools will greatly facilitate the identification of such strains. A sensitive and specific DNA probe for EAggEC has 
been constructed from a 1-kb fragment of DNA from the $60-\mathrm{MDa}$ plasmid of the prototype strain (17-2) isolated from a Chilean patient [22]. Based on the sequence of a fragment of the EAggEC probe, a PCR assay has been developed to identify EAggEC infection [23]. Some reports suggest that aggregative adherence fimbriae are not universally present in organisms that clearly have the aggregative phenotype $[13,24]$.

The present study was initiated to assess the importance of EAggEC as a possible aetiological agent of acute diarrhoea among children in Calcutta, India. The $E$. coli isolates obtained by coproculture were examined for mannose-resistant aggregative adherence to HeLa cells. Simultaneously the use of a previously described PCR diagnostic system [23] was assessed to characterise $E$. coli strains manifesting a true aggregative pattern of adherence.

\section{Materials and methods}

\section{Study population}

This hospital-based case-control study was done between May 1996 and April 1997. A total of 254 children aged $<5$ years, with acute diarrhoea, who were admitted to the Diarrhoea Treatment and Training Unit of the Dr B. C. Roy Memorial Hospital for Children, Calcutta, without any history of prior antibiotic therapy, were enrolled as cases in the study irrespective of type and duration of diarrhoea. Children (134) matched for age, sex, nutritional status and socioeconomic status, who attended the paediatric clinic of that hospital without any history of diarrhoea or antibiotic therapy for the previous 2 weeks, were also included as controls. One control child was enrolled for every two diarrhoeic children and the seasonal distribution of controls and patients with diarrhoea was similar.

Acute diarrhoea was defined as an attack of sudden onset with passage of three or more liquid or semisolid stools or one stool with altered consistency and blood within $24 \mathrm{~h}$. Diarrhoeal episodes separated by $\geqslant 48 \mathrm{~h}$ were considered to be distinct episodes.

\section{Microbiological methods}

Stool samples were collected from the study population and were examined in the microbiology laboratory within $2 \mathrm{~h}$ of collection for the detection of enteropathogens. Stool samples were examined microscopically for trophozoites and cysts of Entamoeba histolytica and Giardia lamblia. Oocysts of Cryptosporidium spp. were also sought by the acid-fast ZiehlNeelsen method. All samples were also tested for the presence of rotavirus antigen by PAGE. Identification of Shigella, Salmonella, Aeromonas and Campylobacter spp., Vibrio cholerae and $V$. parahaemolyticus isolates was performed by standard methods [25].

\section{Identification of E. coli strains}

Two lactose-fermenting and one (if any) non-lactosefermenting colonies on a MacConkey Agar (Difco) plate were selected randomly from each patient and control and tentatively identified by biochemical tests as $E$. coli. Identified colonies were preserved on Dorset egg-yolk slants and tested blind by the following methods, independently.

\section{Differentiation of pathogenic E. coli strains}

A total of $803 E$. coli isolates from 388 samples was tested by a PCR technique [26] with oligonucleotide primers to differentiate enterotoxigenic $[27,28]$, verotoxigenic [29] and enteroinvasive [30] E. coli (ETEC, VTEC and EIEC). Each strain could be identified by its distinct amplicon size. The specific D-mannose-resistant adherence patterns of localised, diffuse and enteroaggregative $E$. coli were detected by $\mathrm{HeLa}$ cell adherence assay as described previously [31]. Suitable positive and negative control strains were included in each study.

\section{HeLa cell adherence assay}

Briefly, $20 \mu \mathrm{l}$ of an overnight bacterial culture in Tryptic Soy Broth (Difco) were inoculated onto a monolayer of HeLa cells on glass coverslips in tissue culture plates, in the presence of methyl- $a$-D-mannoside $1 \%$, and incubated at $37^{\circ} \mathrm{C}$ with $\mathrm{CO}_{2} 10 \% \mathrm{v} / \mathrm{v}$ for $3 \mathrm{~h}$. The petri dishes were washed three times, cells were fixed with methanol $70 \% \mathrm{v} / \mathrm{v}$ and stained with Giemsa $10 \%$ stain. Coverslips were mounted on glass slides and examined for adherence at $\times 1000$ magnification by light microscopy.

\section{Additional EAggEC characterisation by $P C R$}

All E. coli isolates were suspended in Luria Broth (Difco) and incubated at $100^{\circ} \mathrm{C}$ for $20 \mathrm{~min}$. The boiled suspension was used as the source of DNA for PCR. The oligonucleotide primers PCVD 432/start (5' CTG GCG AAA GAC TGT ATC AT-3') and PCVD 432/stop (5' CAA TGT ATA GAA ATC CGC TGT T-3') were selected from the EaggEC probe [23]. The reaction mixture $(50 \mu \mathrm{l})$ consisted of boiled suspension $10 \mu 1,50 \mathrm{mM} \mathrm{KCl} 10 \mathrm{mM} \mathrm{MgCl}_{2}$, gelatin $0.01 \%$, $0.25 \mathrm{mM}$ each deoxynucleotide triphosphates, $50 \mathrm{pM}$ of each primer and 2 units of Taq polymerase. The amplification was performed in a thermocycler (FTS 320 , Corbett Research, Australia) for 30 cycles $\left(94^{\circ} \mathrm{C}\right.$ for $40 \mathrm{~s}, 53^{\circ} \mathrm{C}$ for $60 \mathrm{~s}, 72^{\circ} \mathrm{C}$ for $60 \mathrm{~s}$ ) followed by a final extension at $72^{\circ} \mathrm{C}$ for $10 \mathrm{~min}$. The identity of the amplified band at the 630-bp region was confirmed by Southern hydridisation with the specific probe for aggregative adherence [22]. Signals were visualised by chemiluminescence (ECL; Amersham, Life Science). Strain 17-2 was used as a positive control and reaction mixture without template DNA was used as reagent 
control in each batch of tests. A comparison was made between the results obtained by the PCR method in relation to the results obtained by the HeLa cell adhesion method.

\section{Serogrouping and antimicrobiol susceptibility patterns of EAggEC strains}

The enteroaggregative $E$. coli strains isolated from stool samples were further characterised for their $O$ serogroup by slide agglutination with polyvalent and monovalent antisera (Denka, Seiken, Japan) against the following $\mathrm{O}$ antigens: $\mathrm{O} 1, \mathrm{O} 6, \mathrm{O} 8, \mathrm{O} 15, \mathrm{O} 18, \mathrm{O} 20$, O25, O26, O27, O28ac, O29, O44, O55, O63, O78, O85a, O111, O112ac, O114, O115, O119, O124, O125, O126, O127a, O128, O136, O142, O143, O144, O146, O148, O151, O152, O157, O158, O159, O164, O166, O167, O168 and O169. Serogroups were confirmed by test-tube agglutination by standard procedures. The strains showing autoagglutination were reported as rough strains.

Antimicrobial susceptibility testing was done by the disk diffusion method in accordance with National Committee for Clinical Laboratory Standards guidelines.

\section{Statistical analysis}

Fisher's two-tailed exact test and the $\chi^{2}$ test were used for statistical analysis. Odds ratio (OR) with $95 \%$ confidence intervals (CI) were used as measures of association; $\mathrm{p}<0.05$ was considered significant.

\section{Results}

During the 1-year study period, 254 children $<5$ years of age admitted to the children's hospital had acute diarrhoea. The median age was $11(\min 1, \max 60)$ months, and $104(41 \%)$ patients were girls. Of the 254 cases, $180(71 \%)$ had watery diarrhoea and $74(29 \%)$ had mucoid diarrhoea with or without blood. Standard culture techniques detected bacterial, viral and parasitic enteropathogens in the stool of $180(71 \%)$ diarrhoeic children and $16(12 \%)$ healthy children. Multiple pathogens were detected in $43(17 \%)$ cases and only $2(1.5 \%)$ control children. The sole enteropathogens identified from cases were rotavirus $(4.9 \%)$, Shigella spp. $(4.1 \%)$ Salmonella spp. $(2.3 \%), \quad V$ cholerae (1.9\%), Campylobacter spp. (2.2\%), Aeromonas spp. (2.4\%), Cryptosporidium (1.9\%), Giardia lamblia $(1.7 \%)$, Ent. histolytica $(0.8 \%)$.

Diarrhoea-producing $E$. coli constituted the most frequently identified organism, being the sole isolate in $81(31.8 \%)$ cases and $11(8 \%)$ controls $(\mathrm{p}<0.05)$. Enteroadherent $E$. coli represented the most common category among enterovirulent $E$. coli and was identified in $59(23.2 \%)$ cases and $11(8.2 \%)$ controls. The isolation rate of ETEC as sole agent was 8\% (20 of $254)$ in diarrhoeic cases. Patients harbouring EIEC were very uncommon ( 2 of $254 ; 0.7 \%$ ). VTEC were not identified from diarrhoeic cases. Control children did not have ETEC, EIEC or VTEC in their stools.

\section{Identification and characterisation of EAggEC strains}

EAggEC organisms in this study were identified primarily by phenotype, so all strains considered to be EAggEC were phenotypically positive, by definition, in the adherence assay. Table 1 shows that the isolation rate of EAggEC from cases (25 of $254 ; 9.8 \%$ ) was significantly $(\mathrm{p}<0.05)$ higher than that from controls ( 3 of $134 ; 2.2 \%$ ). Overall, there was an association between the presence of EAggEC in stool and acute diarrhoea (OR, 4.8; 95\% CI: $1.41,25.1$ ) in children.

However, age stratification showed the highest (4 of 26; $15.4 \%$ ) isolation rate of EAggEC in infants aged $<6$ months (Table 2). Yet, because of the small sample size, the $95 \%$ CIs are broad, from $+1 \%$ to $-29 \%$. In children $>36$ months, the presence of EAggEC in stool was not associated with diarrhoea.

Table 3 presents the clinical profiles of the patients infected solely with EAggEC. In four diarrhoeal children and one control child, EAggEC were isolated in association with other enteropathogens, e.g., rotavirus (two cases), $V$. cholerae (two cases), camplyobacter (one control).

Table 4 shows a comparison of the results obtained by

Table 1. HeLa cell adhesion of enteroadherent E. coli isolated as sole pathogen

\begin{tabular}{lccl}
\hline & \multicolumn{3}{c}{$\begin{array}{c}\text { Number (\%) of infected } \\
\text { children }\end{array}$} \\
\cline { 2 - 3 } $\begin{array}{l}\text { isolates } \\
\text { with types } \\
\text { of adhesion }\end{array}$ & $\begin{array}{c}\text { diarrhoeal } \\
(254)\end{array}$ & $\begin{array}{c}\text { non-diarrhoeal } \\
(134)\end{array}$ & $\mathrm{p}$ value \\
\hline LAEC & $16(6.3)$ & $1(0.7)$ & $0.006^{*}$ \\
DAEC & $18(7.1)$ & $7(5.2)$ & $0.48^{\dagger}$ \\
EAggEC & $25(9.8)$ & $3(2.2)$ & $0.003^{*}$ \\
Total & $59(23.2)$ & $11(8.2)$ & $0.0001^{*}$ \\
\hline
\end{tabular}

LAEC, localised adherent E. coli; DAEC, diffuse adherent E. coli; EAggEC, aggregative adherent $E$. coli.

*Fisher's exact test.

${ }^{\dagger} \chi^{2}$ test.

Table 2. Age distribution of 388 children with or without diarrhoea from whom EAggEC were isolated

\begin{tabular}{|c|c|c|}
\hline \multirow{2}{*}{$\begin{array}{l}\text { Age groups } \\
\text { (months) }\end{array}$} & \multicolumn{2}{|c|}{$\begin{array}{c}\text { Number of infected children/number of } \\
\text { children studied }(\%)\end{array}$} \\
\hline & Cases & Control \\
\hline$<6$ & $4 / 26 \quad(15.4)$ & $0 / 14$ \\
\hline $6-12$ & $14 / 138(10.1)$ & $1 / 73$ \\
\hline $13-24$ & $4 / 50$ & $0 / 26$ \\
\hline $25-36$ & $2 / 23$ & $0 / 12$ \\
\hline$>36$ & $1 / 17$ & $2 / 9 \quad(22.2)$ \\
\hline Total & $25 / 254 \quad(9.8)$ & $3 / 134 \quad(2.2)$ \\
\hline
\end{tabular}


Table 3. Clinical profile of 25 children with diarrhoea solely infected with EAggEC

\begin{tabular}{lc}
\hline Characteristics & \\
\hline Age (months): & $10(3.38)$ \\
median (min, max) & $3(1,15)$ \\
Duration of diarrhoea in day before & \\
$\quad$ hospitalisation: & \\
median (min, max) & Number $(\%)$ of children \\
\cline { 2 - 2 } & $15(60): 10(40)$ \\
Male:female & $18(72)$ \\
Stool character & $7(28)$ \\
Watery & 0 \\
Mucoid & \\
Bloody & $6(24)$ \\
Dehydration & $9(36)$ \\
None & $10(40)$ \\
Moderate & \\
Severe & $3(12)$ \\
Other features & $4(16)$ \\
Vomiting & $6(24)$ \\
Fever $\left(>38.2^{\circ} \mathrm{C}\right)$ & \\
Abdominal pain & \\
\hline
\end{tabular}

Table 4. Results obtained by PCR for EAggEC in relation to results obtained by $\mathrm{HeLa}$ cell adherence assay

\begin{tabular}{lccc}
\hline & \multicolumn{3}{c}{ HeLa cell adherence results } \\
\cline { 2 - 4 } PCR result & Positive* $^{*}$ & Negative & Total \\
\hline Positive & 26 & 9 & 35 \\
Negative & 7 & 346 & 353 \\
Total & 33 & 355 & 388 \\
\hline
\end{tabular}

Data are expressed as number of infected children.

${ }^{*}$ Positive for aggregative adherence.

PCR with those obtained by HeLa cell culture in the detection of EAggEC infection in children with or without diarrhoea. The PCR assay correctly detected EAggEC infection in 26 children, although 33 children showed the presence of EAggEC in their stools by HeLa cell adherence assay. Therefore, PCR failed to detect the infection in seven children from whom EAggEC were detected by HeLa cell culture. PCR was not positive for strains showing localised adherence. Nine samples showed positivity by PCR alone, of which $E$. coli isolates from two samples showed the diffuse type of adherence, and other strains did not show the typical stacked-brick appearance in the HeLa cell assay. Hence, the PCR assay was moderately sensitive $(78 \%)$ and specific $(97 \%)$ in this study. The hands-on time required in the laboratory to perform the PCR was only $2 \mathrm{~h}$ (SD 1.8) for testing 20 samples. Samples could be processed within 1 day after collection and overnight growth; the mean time required for the diagnosis of positive or negative samples by PCR assay, was $27 \mathrm{~h}$ (SD 5.6).

The results of analysing EAggEC isolates by HeLa cell assay, PCR assay and $\mathrm{O}$ serogroups are shown in Table 5. The $O$ serogroups identified among the EAggEC isolates in this study were $\mathrm{O} 44$ (two strains), $\mathrm{O} 128$
Table 5. Analysis of the sole EAggEC isolates by HeLa cell culture, PCR and $\mathrm{O}$ serogrouping

\begin{tabular}{|c|c|c|}
\hline \multirow[b]{2}{*}{$\begin{array}{l}\text { EAggEC strains } \\
\text { isolated }\end{array}$} & \multicolumn{2}{|c|}{ Number $(\%)$ of infected children } \\
\hline & $\begin{array}{l}\text { Cases } \\
(254)\end{array}$ & $\begin{array}{l}\text { Controls } \\
\text { (134) }\end{array}$ \\
\hline $\mathrm{AA}^{+}, \mathrm{PCR}^{+}$ & $21(8.2)$ & $3(2.2)$ \\
\hline O serogroup & 10 & 1 \\
\hline OUT & 11 & 2 \\
\hline $\mathrm{AA}^{+}, \mathrm{PCR}^{-}$ & $4(1.5)$ & 0 \\
\hline O serogroup & 0 & 0 \\
\hline OUT & 4 & 0 \\
\hline $\mathrm{AA}^{-}, \mathrm{PCR}^{+}$ & $3(1.2)$ & $2(1.5)$ \\
\hline O serogroup & 1 & 0 \\
\hline OUT & 2 & 2 \\
\hline
\end{tabular}

AA, aggregative adherence to HeLa cells; OUT, O serogroup untypable.

(three), O111 (three), O114 (one), O1 (one), O86 (one) and 17 strains were $\mathrm{O}$ untypable. Antimicrobial susceptibility patterns of the EAggEC isolates were uniformly $(100 \%)$ resistant to ampicillin/amoxycillin and furazolidone; $>80 \%$ of strains were resistant to tetracycline and co-trimoxazole, $50 \%$ were resistant to nalidixic acid and $33 \%$ were resistant to chloramphenicol. However, almost all strains were uniformly (>98\%) sensitive to gentamicin, amikacin, norfloxacin, ciprofloxacin and cefotaxime; only one strain showed resistance to norfloxacin and ciprofloxacin.

The EAggEC strains isolated in this study did not possess enterotoxin genes (LT, ST or VT) or the enteroinvasive gene, as determined by PCR.

\section{Discussion}

The role of localised adherent $E$. coli as an important diarrhoea-causing agent in hospitalised infants in Calcutta, India was reported in a previous study [21], but EAggEC were not identified. The present study describes the association of EAggEC with acute diarrhoea in children (predominantly infants) in Calcutta; although the association decreased with age in children aged $>36$ months. This observation was in accord with the observations of an earlier study [9], in which EAggEC was isolated significantly more frequently from patients with acute diarrhoea than from controls in the $0-2$ months age group. Further studies are required to elucidate the risk factors among infants for developing diarrhoea due to EAggEC.

The clinical characteristics of diarrhoeic children infected solely with EAggEC indicated that acute watery diarrhoea $(72 \%)$ was more frequent than mucoid diarrhoea $(28 \%)$. None of the children had blood in the stool. Bhan et al. [5] reported gross blood in the stools of $12.2 \%$ of cases infected with EAggEC. The median age of infection of EAggEC was 10 months (min 3, $\max 38$ ) and median duration of 
diarrhoea was 3 days ( $\min 1, \max 15)$. Of 10 severely dehydrated children, nine were infants, three of whom experienced vomiting and required intravenous fluid for correction of dehydration. Fever and abdominal colic were detected in 16 and $24 \%$ of the infected children respectively. However, abdominal colic was observed more frequently among infected individuals in other studies [32].

The epidemiology of EAggEC has been difficult to study, because of difficulties in identifying the organism from stool cultures. Further studies are required to determine the source and transmission of infection for the development of effective control strategies to contain the infection. Recent reports of outbreaks [12-14] by EAggEC also support the need for epidemiological studies. Although EAggEC were originally identified by the HEp2 (or HeLa) adherence assay, this technique is cumbersome and inefficient if large numbers of samples are to be analysed, particularly in epidemiological studies. On the other hand $\mathrm{O}$ serogrouping is of little value in the identification of EAggEC, because in the present study only $39 \%$ of EAggEC isolates were O typable and they belonged to a number of $\mathrm{O}$ serogroups. Serotyping with specific ' $\mathrm{H}$ ' antisera was not technically possible in this study. However, a similar observation of $\mathrm{O}$ untypable diarrhoea-associated EAggEC has been documented by other workers [9]. Hence, the use of molecular diagnostic systems in larger scale field studies needs to be evaluated.

The present study evaluated a PCR method described in an earlier report [23]. The data suggested $78 \%$ sensitivity and $97 \%$ specificity for this PCR method as compared with cell adhesion, which indicated considerable although not perfect correlation between the two methods. It was also observed that PCR was less timeconsuming and simpler to perform then the cell culture technique. With proper standardisation, PCR may be performed directly on stool samples. However, to determine pathogenicity, it is necessary to identify the disease-causing strains.

Although it has been shown that these EAggEC strains lacked pathogenic factors such as the ability to express enterotoxins (LT, ST, VT) and invasiveness, studies are in progress to determine the possible virulence mechanisms, to explain the pathogenicity of EAggEC in children. The anomalies with respect to those strains detected by PCR alone or cell culture alone are to be studied in greater detail, to determine whether heterogenicity in PCR positivity is correlated with genetically heterogenous types and virulence traits of EAggEC strains. Similar observations have been documented in previous studies [12, 24]. The reason why some EAggEC did not show positive results in the PCR assay is unknown [23], it is possible that there is sequence variation in the primer binding sites of those strains. Other diagnostic tools may be needed to identify $20 \%$ ( 7 of 33 ) of the strains that were culture positive but PCR negative.

The antimicrobial susceptibility patterns of the EAggEC isolates showed multiple antibiotic resistance. Almost $60 \%$ of the isolated strains were resistant to five or more drugs and $22 \%$ were resistant to seven or more drugs. A previous study reported that EAggEC are fairly resistant to antibiotics and suggested that resistance may be linked to virulence [33]. Thus, a treatment schedule for children should consider the antibiotic resistance patterns of the local isolates. However, the role of chemotherapy in the treatment of EAggEC-associated diarrhoea is yet to be assessed.

Thus, the results suggest that EAggEC plays an important role in the aetiology of acute diarrhoea among infants in India and the PCR diagnostic system may be useful in epidemiological studies to identify EAggEC infection, although the definitive test for EAggEC remains the cell adherence assay.

We thank Dr J. P. Nataro, Centre for Vaccine Development, Baltimore, MD, USA for supplying the EAggEC probe-containing strain and control strain. The support of Dr S. K. Bhattacharya, Director, NICED, is gratefully acknowledged.

\section{References}

1. Ulshen MH, Rollo JL. Pathogenesis of Escherichia coli gastroenteritis in man - another mechanism. N Engl J Med 1980; 302: 99-101.

2. Mathewson JJ, Cravioto A. HEp-2 cell adherence as an assay for virulence among diarrheagenic Escherichia coli. $J$ Infect Dis 1989; 159: 1057-1060.

3. Nataro JP, Kaper JB, Robins-Browne R, Prado V, Vial P, Levine MM. Patterns of adherence of diarrheagenic Escherichia coli to HEp-2 cells. Pediatr Infect Dis J 1987; 6: $829-831$.

4. Vial $\mathrm{P}$, Robins-Browne $\mathrm{R}$, Lior $\mathrm{H}$ et al. Characterization of enteroadherent-aggregative Escherichia coli, a putative agent for diarrheal disease. $J$ Infect Dis 1988; 158: 70-79.

5. Bhan MK, Raj P, Levine MM et al. Enteroaggregative Escherichia coli associated with persistent diarrhea in a cohort of rural children in India. $J$ Infect Dis 1989; 159: 1061-1064.

6. Cravioto A, Tello A, Navarro A et al. Association of Escherichia coli HEp-2 adherence patterns with type and duration of diarrhoea. Lancet 1991; 337: 262-264.

7. Wanke CA, Schorling JB, Barrett LJ, Desouza MA, Guerrant RL. Potential role of adherence traits of Escherichia coli in persistent diarrhea in an urban Brazilian slum. Pediatr Infect Dis $J$ 1991; 10: 764-751.

8. Levine MM, Prado V, Robins-Browne $\mathrm{R}$ et al. Use of DNA probes and HEp-2 cell adherence assay to detect diarrheagenic Escherichia coli. J Infect Dis 1988; 158: 224-227.

9. González R, Díaz C, Mariño M, Cloralt R, Pequeneze M, Pérez-Schael I. Age-specific prevalence of Escherichia coli with localized and aggregative adherence in Venezuelan infants with acute diarrhea. J Clin Microbiol 1997; 35: 1103-1107.

10. Echeverria $\mathrm{P}$, Serichantalerg $\mathrm{O}$, Changchawalit et al. Tissue culture-adherent Escherichia coli in infantile diarrhea. $J$ Infect Dis 1992; 165: 141-143.

11. Gomes TAT, Blake PA, Trabulsi LR. Prevalence of Escherichia coli strains with localized, diffuse, and aggregative adherence to HeLa cells in infants with diarrhea and matched controls. $J$ Clin Microbiol 1989; 27: 266-269.

12. Smith HR, Cheasty T, Rowe B. Enteroaggregative Escherichia coli and outbreaks of gastroenteritis in UK. Lancet 1997; 350: 814-815.

13. Itoh Y, Nagano I, Kunishima M, Ezaki T. Laboratory 
investigation of enteroaggregative Escherichia coli $\mathrm{O}$ untypeable: $\mathrm{H} 10$ associated with a massive outbreak of gastrointestinal illness. $J$ Clin Microbiol 1997; 35: 2546-2550.

14. Čbeljić M, Miljković-Selimović B, Paunovic-Todosijević D et al. Enteroaggregative Escherichia coli associated with an outbreak of diarrhoea in a neonatal nursery ward. Epidemiol Infect 1996; 117: 11-16.

15. Nataro JP, Deng Y, Maneval DR, German AL, Martin WC, Levine MM. Aggregative adherence fimbriae I of enteroaggregative Escherichia coli mediate adherence to HEp-2 cells and hemagglutination of human erythrocytes. Infect Immun 1992; 60: 2297-2304.

16. Czeczulin J, Balepur S, Hicks S et al. Aggregative adherence fimbria II, a second fimbrial antigen mediating aggregative adherence in enteroaggregative Escherichia coli. Infect Immun 1997; 65: 4135-4145.

17. Savarino SJ, Fasano A, Watson $\mathrm{J}$ et al. Enteroaggregative Escherichia coli heat-stable enterotoxin 1 represents another subfamily of E. coli heat-stable toxin. Proc Natl Acad Sci USA 1993; 90: 3093-3097.

18. Baldwin TJ, Knutton S, Sellers L, Manjarrez Hernandez HA Aitken A, Williams PH. Enteroaggregative Escherichia coli strains secrete a heat-labile toxin antigenically related to $E$. coli hemolysin. Infect Immun 1992; 60: 2092-2095.

19. Nataro JP, Yikang D, Cookson S et al. Heterogeneity of enteroaggregative Escherichia coli virulence demonstrated in volunteers. J Infect Dis 1995; 171: 465-468.

20. Eslava C, Navarro-García F, Czeczulin JR, Henderson IR, Carvioto A, Nataro JP. Pet, an autotransporter enterotoxin from enteroaggregative Escherichia coli. Infect Immun 1998; 66: 3155-3163.

21. Ghosh AR, Nair GB, Naik TN, Paul M, Pal SC, Sen D. Entero-adherent Escherichia coli is an important diarrhoeagenic agent in infants aged below 6 months in Calcutta, India. $J$ Med Microbiol 1992; 36: 264-268.

22. Baudry B, Savarino SJ, Vial P, Kaper JB, Levine MM. A sensitive and specific DNA probe to identify enteroaggregative Escherichia coli, a recently discovered diarrheal pathogen. $J$ Infect Dis 1990; 161: 1249-1251.
23. Schmidt H, Knop C, Franke S, Aleksic S, Heesemann J, Karch H. Development of PCR for screening of enteroaggregative Escherichia coli. J Clin Microbiol 1995; 33: 701-705.

24. Polotsky Y, Nataro JP, Kotler D, Barrett TJ, Orenstein JM HEp-2 cell adherence patterns, serotyping, and DNA analysis of Escherichia coli isolates from eight patients with AIDS and chronic diarrhea. J Clin Microbiol 1997; 35: 1952-1958.

25. World Health Organization. Manual of laboratory investigation of acute enteric infections. Mimeographed documents. Geneva, WHO 1983 (WHO/CDD/63.3 rev).

26. Tornieporth NG, John J, Salgado $\mathrm{K}$ et al. Differentiation of pathogenic Escherichia coli strains in Brazilian children by PCR. J Clin Microbiol 1995; 33: 1371-1374.

27. Yamamoto T, Tamura T, Yokota T. Primary structure of heatlabile enterotoxin produced by Escherichia coli pathogenic for humans. J Biol Chem 1984; 259: 5037-5044.

28. Moseley SL, Hardy JW, Huq MI, Echeverria P, Falkow S Isolation and nucleotide sequence determination of a gene encoding a heat-stable enterotoxin of Escherichia coli. Infect Immun 1983; 39: 1167-1174.

29. Yamasaki S, Lin Z, Shirai $\mathrm{H}$ et al. Typing of verotoxins by DNA colony hybridization with poly- and oligonucleotide probes, a bead-enzyme-linked immunosorbent assay and polymerase chain reaction. Microbiol Immunol 1996; 40: $345-352$.

30. Venkatesan MM, Buysse JM, Kopecko DJ. Use of Shigella flexneri ipaC and ipaH gene sequences for the general identification of Shigella spp. and enteroinvasive Escherichia coli. J Clin Microbiol 1989; 27: 2687-2691.

31. Scaletsky ICA, Silva MLM, Trabulsi LR. Distinctive patterns of adherence of enteropathogenic Escherichia coli to HeLa cells. Infect Immun 1984; 45: 534-536.

32. Huppertz H-I, Rutkowski S, Aleksic S, Karch H. Acute and chronic diarrhoea and abdominal colic associated with enteroaggregative Escherichia coli in young children living in western Europe. Lancet 1997; 349: 1660-1662.

33. Yamamoto T, Echeverria P, Yokota T. Drug resistance and adherence to human intestines of enteroaggregative Escherichia coli. J Infect Dis 1992; 165: 744-749. 